\title{
Adaptive control of ore mill charge
}

\author{
Natalia Morkun ${ }^{1 *}$, Tetiana Oliinyk $^{2}$, Iryna Kasatkina ${ }^{3}$, and Oleksandr Rytsko ${ }^{4}$ \\ ${ }^{1}$ Kryvyi Rih National University, Department of Automation, Computer Science and Technology, \\ 11 Matusevycha St., 50027 Kryvyi Rih, Ukraine \\ ${ }^{2}$ Kryvyi Rih National University, Department of Mineral Processing and Chemistry, 11 Matusevycha \\ St., 50027 Kryvyi Rih, Ukraine \\ ${ }^{3}$ Kryvyi Rih National University, Department of Automation Electromechanical Systems in the Industry \\ and Vehicles, 11 Matusevycha St., 50027 Kryvyi Rih, Ukraine \\ ${ }^{4}$ Kryvyi Rih National University, Graduate student, 11 Matusevycha St., 50027 Kryvyi Rih, Ukraine
}

\begin{abstract}
The system of mining operations does not enable long-lasting mining of single-type ores that causes instability of mineral materials intended for concentration. To solve the problem of controlling these processes on the basis of operating data on characteristics of processed raw materials, the method of controlling mill charge is suggested considering measurements of its output product. This method is based on correlation of the output product quantity and the rate of the mill charge. The process of the object's operation is modeled, while time characteristics of the output controlled value and the mill charge are approximated to assess accuracy of the method of determining the mill charge. The possibility to use the discrete Kalman filter is studied in order to indentify the object's characteristics under noises by measurement results. It is shown that application of the Kalman filter to controlling the mill charge enables not only solving the problem of filtration aimed to obtain data on the object's current state, but also predicting its state.
\end{abstract}

\section{Introduction}

Development of resource-saving technologies and automated control means for ore mining and processing is required to assure competitive products of mining and concentration enterprises of Kryvyi Rih iron ore basin. In particular, selective mining enables iron content increase in the ore mined $[1-3]$.

It should be noted that quality of iron ore materials has deteriorated in recent decades. This leads to the fact that a significant amount of ore materials cannot be processed by concentration plants to produce a concentrate suitable for metallurgical treatment. The problem becomes more complicated because of high specific energy-intensity of production and the necessity to process several mineral-technological types of ore [4-6].

From five to eight mineral-technological types of ore are currently processed at national mining and concentration works. Each type can be characterized by a wide range of sizes of valuable component impregnations in the ore. To expose the valuable component to the fullest, one should form a certain granulometric composition that has to be maintained in all

\footnotetext{
${ }^{*}$ Corresponding author: nmorkun@gmail.com
} 
operational modes of technological equipment [7 - 9].

However, the system of mining operations does not enable long-lasting mining of single-type ores that causes instability of mineral materials intended for concentration. As a result, there appears a necessity of frequent readjustments of certain parameters of the technological mode that deteriorates efficiency of ore treatment $[10-11]$.

In these conditions, frequent readjustments of separate parameters of technological aggregates are required. To do this, the following problem should be solved: obtainment of operating data on a technological process and formation of control which is optimal for current characteristics of processed ore materials. [12 - 15] indicate that in concentration production conditions, ultrasonic means of non-destructive control can be applied to measuring characteristics of ore materials in technological flows. It is worth noting that application of ultrasonic methods can be expedient in solving the problems of concentration intensification as well [16-18].

Yet, even if sufficient amount of operating data on a technological process is available, formation of control for concentration processes becomes complicated due to nonstationarity of their parameters $[19-21]$. There should be considered significant transport delay of information that for several processes, in particular grinding, can be within $15-20$ minutes. It is noteworthy that grinding and sorting are the most energyintensive among concentration processes. Thus, increased efficiency of controlling these processes will enable a significant effect.

There are suggested various approaches to solving the problem of controlling ore grinding and sorting under conditions of uncertainty and nonstationarity of parameters [22-24].

It is indicated in [22] that grinding control is an unconventional problem because of complicated measurements of process parameters and synthesis of its accurate model. To solve this problem, there is a model based on the neural network technology. It is also highlighted that the offered method critically depends on quality of the data intended for model training.

To stabilize the mill charge mode and increase energy efficiency, [23] suggests a system of fuzzy expert control. In this case, the control fuzzy system is intended to calculate signals for distributed contours of controlling individual aggregates. Yet, little attention is paid to the problem of operating control of grinding in an individual aggregate considering characteristics of the processed ore.

To model the grinding-sorting cycle, [24] offers a phenomenological non-linear balance model. Control is suggested to be performed by means of single input-output fractionalorder controllers adjusted by offline optimization.

Thus, the problem of increasing efficiency of control over grinding-sorting processes under uncertainty and nonstationarity of parameters is topical. It is necessary to improve corresponding simulation and control means to solve the problem of controlling these processes on the basis of operating data on characteristics of the processed raw materials.

\section{Mathematical representation and description of grinding processes}

Let us consider the algorithm of mill charging based on measuring the quantity of the end product. The algorithm involves correlation of the quantity of the end product and the rate of mill charge.

Let us consider the transfer function of the object under study to be the first-order relaxation circuit звеном (Fig. 1). The input value $X(t)$ conditioning mill capacity is a controlled variable which is correlated with the mill charge $P(t)$. Input product sorting results in part of the product being returned for re-grinding. The fraction of the returned 
product $\alpha(t)$ depends on the mill operation mode determined, in turn, by the value of mill charge. Product sorting and return for re-grinding has its own delay time. This delay is small if a hydrocyclone is used as a sorting machine. Yet, the problem does not lose its generality even without this condition. Therefore, to simplify mathematical computations, we are going to treat this problem within the given approximations.

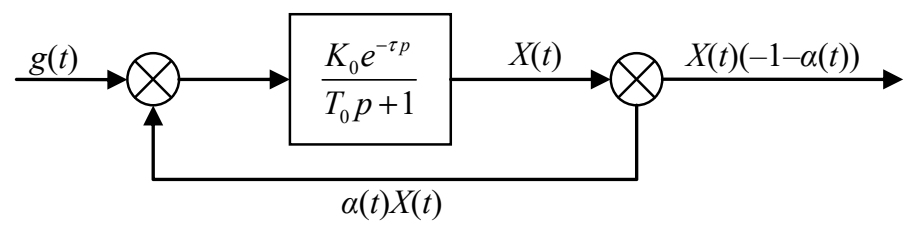

Fig. 1. The scheme of the controlled object.

If we denote the value of charged material in the mill (i.e. the amount of ore and water per time unit) by $g(t)$, the controlled input value $X(t)$ can be presented as

$$
\mathrm{X}(\mathrm{t})=\frac{K_{0}}{T_{0}} \int_{0}^{t-\tau} e^{-\frac{\mathrm{t}-\tau-\mathrm{u}}{\mathrm{T}_{0}}}[g(u)+\alpha(u) X(u)] d u .
$$

After replacing the variable $\tilde{t}=t-\tau$ from the integral expression (1), we proceed to the differential form

$$
\dot{X}(\tilde{t}+\tau)+\frac{X(\tilde{t}+\tau)}{T_{0}}=\frac{K_{0}}{T_{0}}[g(\tilde{t})+\alpha(\tilde{t}) X(\tilde{t})] .
$$

In the right part of (2), in the square brackets, there is a value determining the amount of material charged into the mill per time unit. The change of the mill charge $P(t)$ is determined by the difference between the quantity of the material charged into the mill and the quantity of the material discharged. Thus, during the small time period $\Delta t$, the mill charge is changed for the value

$$
P(t+\Delta t)-P(t)=[g(t)+\alpha(t) X(t)-X(t)] \Delta t .
$$

Expanding the value $P(t+\Delta t)$ to series in the value $\Delta t$, we obtain the differential equation

$$
\frac{d P(t)}{d t}=g(t)+\alpha(t) X(t)-X(t) .
$$

As is seen from equation (4), the quantity of the input material can be expressed by the changed mill charge, i.e.

$$
g(t)+\alpha(t) X(t)=\frac{d P(t)}{d t}+X(t)=\dot{P}(t)+X(t) .
$$

Substituting the right part of expression (5) into the right part of (2), we obtain

$$
\dot{X}(\tilde{t}+\tau)+\frac{X(\tilde{t}+\tau)}{T_{0}}=\frac{K_{0}}{T_{0}}[\dot{P}(\tilde{t})+X(\tilde{t})] .
$$

Thus, equation (6) establishes dependency of the controlled output value $X(t)$ and the mill charge $P(t)$. 
It should be noted that for the studied object, the statistic transfer coefficient $K_{0}$ is always equal to one and equation (6) looks as follows

$$
\frac{d P(\tilde{t})}{d \tilde{t}}=T_{0} \dot{X}(\tilde{t}+\tau)+X(\tilde{t}+\tau)-X(\tilde{t}) .
$$

Let us expand the value $X(\tilde{t}+\tau)$ to series in the $\tau$ parameter

$$
X(\tilde{t}+\tau)=X(\tilde{t})+\dot{X}(\tilde{t}) \tau+\frac{\ddot{X}(\tilde{t}) \tau^{2}}{2}+\ldots=\sum_{n=0}^{\infty} \frac{X^{(n)}(\tilde{t}) \tau^{n}}{n !}
$$

Then

$$
\begin{aligned}
& X(\tilde{t}+t)-X(\tilde{t})=\dot{X}(\tilde{t}) \tau+\frac{\ddot{X}(\tilde{t}) t^{2}}{2}+\ldots=\frac{\tau}{2} \frac{d}{d t}[2 X(\tilde{t})+\dot{X}(\tilde{t}) \tau+ \\
& \left.+\frac{\ddot{X}(\tilde{t}) \tau^{2}}{3}+\ldots\right] \approx \frac{\tau}{2} \frac{d}{d t}[X(\tilde{t})+X(\tilde{t}+\tau)]=\frac{\tau}{2}[\dot{X}(\tilde{t})+\dot{X}(\tilde{t}+\tau)] .
\end{aligned}
$$

Considering this, equation (7) can be written as

$$
\frac{d P(\tilde{t})}{d \tilde{t}}=\left(T_{0}+\frac{\tau}{2}\right) \dot{X}(\tilde{t}+\tau)+\frac{\tau}{2} \dot{X}(\tilde{t}) .
$$

While integrating the left and the right parts of this equation and returning to the former variable, we obtain

$$
P(t-\tau)=\left(T_{0}+\frac{\tau}{2}\right) X(t)+\frac{\tau}{2} X(t-\tau)+\text { const }
$$

So, quite a simple result is obtained indicating that, up to a constant, the mill charge at the previous moment $t-\tau$ is found through the output controlled value.

Let us assume that the output controlled value $X(t)$ is evaluated by some measurement signal $S(t)$ which is directly proportionate to $X(t)$, i.e. the latter can be presented as

$$
X(t)=a+b S(t) .
$$

Substituting (12) into (11), we obtain

$$
P(t-\tau)=\left(T_{0}+\frac{\tau}{2}\right) b S(t)+\frac{\tau}{2} b S(t-\tau)+\left(T_{0}+\frac{\tau}{2}\right) a+\text { const } .
$$

If there are no known characteristics $T_{0}$ and $\tau$ for an object, the dependency of the mill charge on the signal (13) can be written as:

$$
P(t-\tau)=A S(t)+B S(t-\tau)+C .
$$

The constants $A, B$ and $C$ are determined by the results of preliminary measurements of $P(t)$ and $S(t)$. Let us study this procedure in detail.

To determine the mentioned constants, one should perform n-measurements of the value of the mill charge $P$ and the measurement signal $S$ at the moment $t_{1}-\tau, t_{2}-\tau, \ldots, t_{n}-\tau$, and the signal $S$ at the moments $t_{1}, t_{2}, \ldots, t_{n}$. Next, by the least square method, solutions of a set of equations 


$$
\left\{\begin{array}{l}
A \aleph_{1}+B \lambda_{1}+C \aleph_{0}=\theta_{1} \\
A \lambda_{1}+\mathrm{B} \delta_{1}+\mathrm{C} \delta_{0}=\theta_{2} \\
A \aleph_{0}+\mathrm{B} \delta_{0}+\mathrm{C} n=\theta_{3}
\end{array}\right.
$$

will result in coefficients $A, B$ and $C$ according to the standard procedure

$$
A=\frac{\Delta_{A}}{\Delta}, B=\frac{\Delta_{B}}{\Delta}, C=\frac{\Delta_{C}}{\Delta},
$$

where the determinants

$$
\Delta=\left|\begin{array}{lll}
\aleph_{1} & \lambda_{1} & \aleph_{0} \\
\lambda_{1} & \delta_{1} & \delta_{0} \\
\aleph_{0} & \delta_{0} & n
\end{array}\right| ; \Delta_{\mathrm{A}}=\left|\begin{array}{lll}
\theta_{1} & \lambda_{1} & \aleph_{0} \\
\theta_{2} & \delta_{1} & \delta_{0} \\
\theta_{3} & \delta_{0} & n
\end{array}\right| ; \Delta_{B}=\left|\begin{array}{ccc}
\aleph_{1} & \theta_{1} & \aleph_{0} \\
\lambda_{1} & \theta_{2} & \delta_{0} \\
\aleph_{0} & \theta_{3} & n
\end{array}\right| ; \quad \Delta_{\mathrm{C}}=\left|\begin{array}{ccc}
\aleph_{1} & \lambda_{1} & \theta_{1} \\
\lambda_{1} & \delta_{1} & \theta_{2} \\
\aleph_{0} & \delta_{0} & \theta_{3}
\end{array}\right|
$$

are made of the elements

$$
\begin{aligned}
& \delta_{0}=\sum_{i=1}^{n} S_{i} ; \quad \delta_{1}=\sum_{i=1}^{n} S_{i}^{2} ; \quad \boldsymbol{\aleph}_{0}=\sum_{i=1}^{n} S_{\tau i} ; \quad \boldsymbol{\aleph}_{1}=\sum_{i=1}^{n} S_{\tau i}^{2} \\
& \lambda_{1}=\sum_{i=1}^{n} S_{i} S_{\tau i} ; \quad \theta_{1}=\sum_{i=1}^{n} P_{\tau i} S_{\tau i} ; \quad \theta_{2}=\sum_{i=1}^{n} P_{\tau i} S_{i} ; \quad \theta_{3}=\sum_{i=1}^{n} P \tau i .
\end{aligned}
$$

Here, $S_{i} \equiv S\left(t_{i}\right) ; S_{\tau i} \equiv S\left(t_{i}-\tau\right) ; P_{\tau i} \equiv P\left(t_{i}-\tau\right)$.

To assess accuracy of the method for determining the mill charge, the object's operation is modeled according to its structural scheme (Fig. 1). The divergence of the restored value of the mill charge with the real one does not exceed $4.8 \%$ in conditions of the evident unstable mode of the mill.

When all three constants of the approximated dependency (13) are unknown, the least square method "chooses" their values from the condition of the best approximation of the approximating and the real dependencies in the time interval from $t_{1}$ to $t_{n}$ only according to the results of $n$-measurements.

Yet, this choice of values of the constants can be inappropriate for subsequent time intervals. Therefore, it is desirable to have appropriate data on the object's characteristics $T_{0}$ and $\tau$ and apply approximating dependency (13). In this case, the ratio between the coefficients $A$ and $B\left(A / B=\left(T_{0}+\tau / 2\right) / \tau / 2\right)$ is fixed and it should always be fulfilled.

This enables us to consider that in other time intervals, the approximating dependency will "work" well. In this case, the number of calculated constants reduces simplifying the procedure of their determining. In particular,

$$
b=\frac{\left(\delta_{1} n-\delta_{0} \aleph_{0}\right)}{\left(\aleph_{1} n-\aleph_{0}^{2}\right)} ; \mathrm{C}=\frac{\left(\aleph_{1} \delta_{0}-\aleph_{0} \delta_{1}\right)}{\left(\aleph_{1} n-\aleph_{0}^{2}\right)},
$$

where $\aleph_{0}=\sum_{i=1}^{n} Y_{i} ; \aleph_{1}=\sum_{i=1}^{n} Y_{i}^{2} ; \delta_{0}=\sum_{i=1}^{n} P_{\tau i} ; \delta_{1}=\sum_{i=1}^{n} P_{\tau i} Y_{i} ; Y_{\mathrm{i}}=\left(T_{0}+\frac{\tau}{2}\right) S_{i}+\frac{\tau}{2} S_{\tau i}$.

In case of mill charge calculating by approximating expression (13) with the coefficients found by formula (17), the divergence does not exceed $2.5 \%$. It indicates that the approximation resulting in expression (20) provides a good result even under strict operation modes of the object.

Yet, this expression determines the mill charge only in the previous time moment $t-\tau$, i.e. providing the delayed result for the delay time $\tau$. In order to know the mill charge at the 
measurement time, it is required to predict the controlled value $X(t)$ for the time $\tau$ beforehand. We assume that the state of the system is evaluated at discrete moments $t_{i}$ with the measurement interval corresponding to the delay time $\tau$.

As before, the state of the system (object) is going to be described through the equation

$$
X(k+1)=\phi X(k)+\Gamma W_{\tau}(k),
$$

where $\phi=1-\frac{\tau}{T_{0}} ; \Gamma=\frac{\mathrm{k}_{0} \tau}{\mathrm{T}_{0}} ; \mathrm{W}_{\tau}(k)=g_{\tau}(k)+\alpha X_{\tau}(k)$.

The index $\tau$ of the values $W, g$ and $X$ indicates that they are evaluated in the earlier time period $t=k \tau-\tau$.

The state of $X(k+1)$ can be predicted through the results of measuring the state of $X(k)$ and two previous $X(k-1)$ and $X(k-2)$

$$
X(k+1)=(2+\varphi) X(k)-(2 \varphi+1) X(k-1)+\varphi X(k-2) .
$$

Considering prediction (19) and according to (13), the mill charge $P(k) \equiv P(k \tau)$ can be assessed by the formula

$$
\begin{gathered}
P(k)=b\left(T_{0}+\frac{\tau}{2}\right)(2+\varphi) X(k)+ \\
+b\left\{\frac{\tau}{2}-(2 \varphi+1)\left(T_{0}+\frac{\tau}{2}\right)\right\} X(k-1)+b \varphi X(k-2)+C .
\end{gathered}
$$

Fig. 2 shows the value of the mill charge $P(t)$ (curve 1). According to (20), the value $P(t)$ is assessed at the moment of determining the state of the system $X(t)$ (curve 3 ). Here is a dependency of this value assessed with delay by the value $\tau$ by formula (13), i.e. without prediction results (curve 2). As is seen from the figure, the desire to assess the value of the mill charge at the measurement time causes some inaccuracy.

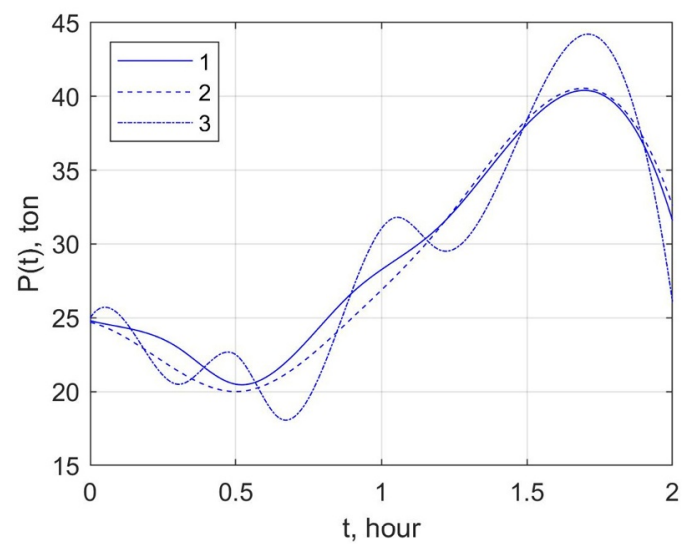

Fig. 2. Dependency of the controlled value and the value of the mill charge.

It is probably impossible to give preference to this or that evaluation without considering the solution of a particular problem. If we lose immediacy, we gain accuracy and vice versa. Therefore, only specifically solved problems of control allow choosing the method of evaluating the value $P$.

Yet in real-life situations, an object's characteristics are usually identified with random noises available. To identify these characteristics, one should distinguish a useful signal of $X(t)$ by measuring $Z(t)$. 


\section{Results and discussion}

We analyze the possibility of applying a discrete Kalman filter [25 - 27] to solving the above problems.

Let us consider the case with the discrete Kalman filter when the state of the system is assessed at the moment of $0, T, 2 T, \ldots, k T, \ldots m T$ with the measurement interval $T$ that varies and is determined by the system characteristics determining, in term, the time of transient processes and other controlled parameters.

The system state is described by the equation

$$
\begin{aligned}
& X(k+1)=\phi(\cdot) X(k)+\Gamma(\cdot) W(k), \\
& Z(k)=H X(k)+\mathrm{V}(k),
\end{aligned}
$$

where $X(k)$ is the $n$-dimensional vector of the state; $W(k)$ is the $l$-dimensional random vector describing the impact on the system; $\varphi(k)$ is the $n \times n$ order matrix; $\Gamma(\cdot)-n \times l$ is the $n \times l-$ dimensional matrix .

The value $\mathrm{Z}(k)$ can be measured if measurement noises $V(k)$ are available. Let us assume that the matrices $\varphi, \Gamma$ and $H$ are composed of constant matrix elements.

Besides, the above vectors meet the conditions

$$
\begin{aligned}
& M W(k)=\bar{W}(k), M V(k)=0, M\left[V(k) \cdot\{V(S)\}^{T}\right]=R(k) \delta(k, S), \\
& M\left[\{W(k)-\bar{W}(k)\}\{W(S)-\bar{W}(S)\}^{T}\right]=Q(k) \delta(k, S),
\end{aligned}
$$

where $\delta(k, S)$ is the Kronecker delta symbol.

In other words, $V(k)$ and $[W(k)-\bar{W}(k)]$ are white noise with zero mathematical expectation.

Based on (21), the system state $\bar{X}(k)$ can be predicted for one time period $T$

$$
\bar{X}(k)=\phi \hat{X}(k-1)+\Gamma \bar{W}(k-1),
$$

where $\hat{X}(k-1)$ is the system state determined by the measurement results $Z(1), Z(2), \ldots$, $Z(k-1)$.

According to the results of $k$-measurements, the state $\hat{X}(k)$ should be assessed by the formula

$$
\hat{X}(k)=\phi \hat{X}(k-1)+\Gamma \bar{W}(k-1)+K(k)[Z(k)-H \bar{X}(k)],
$$

where $K(k)$ is a coefficient of Kalman filter amplification determined either by minimizing the sum of squared errors or by the orthogonal principle and is calculated as follows

$$
\begin{gathered}
K(k)=m(k) H^{T} R^{-1}(k), \\
P(k+1)=N(k+1)-N(k+1) H^{T}\left[H N(k+1) H^{T}+\right. \\
+R(k+1)]^{-1}[H N(k+1)], \\
N(k+1)=\varphi P(k) \varphi^{T}+\partial Q(k) \partial^{T} .
\end{gathered}
$$

Considering (23), equation (24) can be written as

$$
\hat{X}(k)=\bar{X}(k)+K(k)[Z(k)-H \bar{X}(k)] .
$$

If the system state is assessed by the results of $k$-measurements, this assessment is 
filtration. If the state is assessed by the results $(k-1)$ or the smaller number of measurements, this assessment is prediction (forecasting, extrapolation). Let us consider filtration first.

If we assume that during one time period $T$, the input signal $\bar{W}(k)$ does not change much, on the basis of (21) we can consider

$$
\Gamma \bar{W}(k)=\hat{X}(k)-\phi \hat{X}(k-1) .
$$

Using this approximation, the state $\hat{X}(k)$ will be assessed by formula (28) considering (23) and (29)

$$
\begin{aligned}
& \hat{X}(k)=\bar{X}(k)+K(k)[Z(k)-H \bar{X}(k)], \\
& \bar{X}(k)=(1+\varphi) \hat{X}(k-1)-\varphi \hat{X}(k-2) .
\end{aligned}
$$

As is seen from (31) and (30), before assessing the state $\hat{X}(k)$, one should predict the state $\bar{X}(k)$ by formula (30) and then by (15) using the coefficient of Kalman filter amplification $K(k)$ and the result of the $k$-measurement $Z(k)$ to assess it. In this sequence the problem of filtration is solved.

Let us consider the problem of state prediction. We will confine ourselves by predicting only one step ahead, i.e. for the value $T$, in this way assessing $(k+1)$ the system state at the moment $k T$ by the measurement results $\mathrm{Z}(1), \mathrm{Z}(2), \ldots, \mathrm{Z}(k)$. In this case, the sequence of actions seems to change. First, the state $X(k)$ is assessed by the results of $k$-measurements and the prediction of this state at the previous step, i.e. at the moment $(k-1) T$, then the state $k+1$ is predicted. Thus, this procedure is performed by step-by-step application of equations

$$
\begin{gathered}
X(k+1)=\phi X(k)+\Gamma W_{\tau}(k), \\
Z(k)=X(k)+V(k) .
\end{gathered}
$$

Using this system as the initial one, we write the amplification coefficient of the Kalman filter applied to both filtration and prediction of the system. Considering the established denotations, the amplification coefficient will be determined by the formulae

$$
\begin{gathered}
K(k+1)=\frac{\left[\varphi^{2} P(k)+\left(K_{0} T_{0}^{-1}\right)^{2} T q\right] T}{T\left[\varphi^{2} P(k)+\left(K_{0} T_{0}^{-1}\right)^{2} T q\right]+r}, \\
P(k)=\frac{\left[\phi^{2} P(k-1)+\left(K_{0} T_{0}^{-1}\right)^{2} T q\right] r}{T\left[\phi^{2} P(k-1)+\left(K_{0} T_{0}^{-1}\right)^{2} T q\right]+r} .
\end{gathered}
$$

Yet, it should be considered that to assess the object state by the discrete Kalman filter, a priori information on characteristics of the object is required. But determination of object characteristics by the results of assessing the states is the basic moment in the issue of correcting the controller's parameters, i.e. filtration should determine an object's characteristics and not vice versa.

It is essential that application of the discrete Kalman filter can provide data on the current state of the object (the objective of filtration) and it also allows predicting its state (the objective of prediction). If an object's characteristics do not change for a long time or their changes are small and comparable to an identification error with available random noises, it is not reasonable to identify an object's characteristics during every transient process. 
For the objects with time delay, parameters of the controller at input changes of the signal should be controlled by the results of assessing the object with time delay beforehand. That is why, in this case, we should also predict the system state. Besides, the data on the controlled object prediction can be applies to compensating the delay impact on control quality.

Fig. 3 reveals the results of predicting the system state one step beforehand (curve 3).

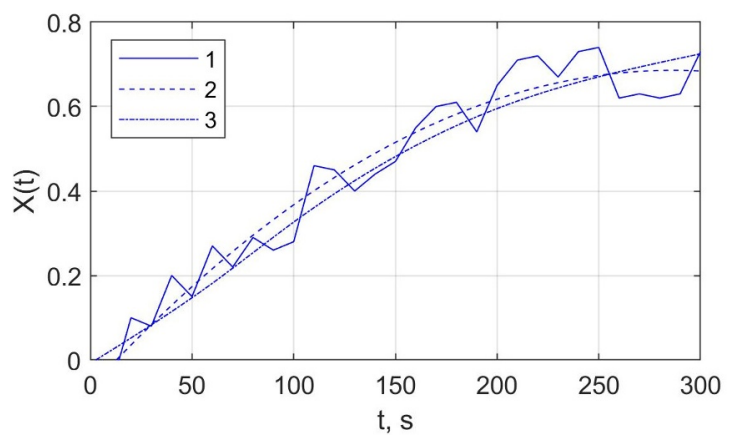

Fig. 3. Results of predicting the system state one step beforehand.

In contrast, there is a curve describing the true state of the system (curve 2) and the results of assessment (filtration) of the controlled value (curve 3). The figure indicates that both prediction and assessment of states at the first moments "react" to changes of the controlled value with delay. This, in turn, is caused by applying approximation (29). Yet, in the studied problem, this drawback of prediction is insignificant.

\section{Conclusions}

It is expedient to apply the adaptation algorithm based on measuring the controlled parameter and its first derivative at the initial stage of the transient process and subsequent correction of PI-controller parameters in the close-loop automated control system of the object the transfer function of which is approximated by the product of two relaxation circuits with delay, only if the value of the time constant of one circuit does not exceed $20 \%$ of the other one. The Kalman filter applied to the adaptation algorithm enables compensating the influence of time delay of the controlled object on control quality. It is shown that application of the Kalman filter to controlling the mill charge enables not only solving the problem of filtration aimed to obtain data on the object's current state, but also predicting its state.

The authors express their sincere gratitude to Kryvyi Rih National University for support in conducting research.

\section{References}

1. Pysmennyi, S., Brovko, D., Shwager, N., Kasatkina, I., Paraniuk, D., \& Serdiuk, O. (2018). Development of complex structure ore deposits by means of chamber systems under conditions of the Kryvyi Rih iron ore field. Eastern-European Journal of Enterprise Technologies, 5(1-95), 3345. https://doi.org/10.15587/1729-4061.2018.142483.

2. Stupnik, N.I., Kalinichenko, V.A., Kolosov, V.A., Pismenniy, S.V., \& Fedko, M.B. (2014). Testing complex-structural magnetite quartzite deposits chamber system design theme. Metallurgical and mining industry, (2), 89-93. 
3. Stupnik, N.I., Fedko, M.B. Pismenniy, S.V. \& Kolosov, V.A. (2014). Development of recommendations for choosing excavation support types and junctions for uranium mines of stateowned enterprise skhidhzk. Naukovyi Visnyk Natsionalnoho Hirnychoho Universytetu, (5), 21-25.

4. Morkun, V., \& Tron, V. (2014). Ore preparation energy-efficient automated control multi-criteria formation with considering of ecological and economic factors. Metallurgical and Mining Industry, (5), 8-10.

5. Morkun, V., Morkun, N., Pikilnyak, A. (2015) Adaptive control system of ore beneficiation process based on Kaczmarz projection algorithm. Metallurgical and Mining Industry, (2), 35-38.

6. Morkun, V., Morkun, N., \& Tron, V. (2015). Formalization and frequency analysis of robust control of ore beneficiation technological processes under parametric uncertainty. Metallurgical and Mining Industry, (5), 7-11.

7. Kupin, A. (2014). Application of neurocontrol principles and classification optimization in conditions of sophisticated technological processes of beneficiation complexes, Metallurgical and Mining Industry, (6), 16-24.

8. Morkun, V., \& Tron, V. (2014). Automation of iron ore raw materials beneficiation with the operational recognition of its varieties in process streams. Metallurgical and Mining Industry, (6), 4-7.

9. Morkun, V., Tron, V., \& Goncharov, S. (2015). Automation of the ore varieties recognition process in the technological process streams based on the dynamic effects of high-energy ultrasound. Metallurgical and Mining Industry, (2), 31-34.

10. Lutsenko, I., Koval, S., Oksanych, I., Serdiuk, O., \& Kolomits, H. (2018). Development of structural-parametric optimization method in systems with continuous feeding of technological products. Eastern-European Journal of Enterprise Technologies, 4(2(94)), 55-62. https://doi.org/10.15587/1729-4061.2018.136609

11. Morkun, V., \& Tcvirkun, S. (2014). Investigation of methods of fuzzy clustering for determining ore types, Metallurgical and Mining Industry, (5), 11-14.

12. Morkun, V., Morkun, N., \& Pikilnyak, A. (2015). The study of volume ultrasonic waves propagation in the gas-containing iron ore pulp. Ultrasonics, (56), 340-343. https://doi.org/110.1016/j.ultras.2014.08.022

13. Morkun, V., Morkun, N., \& Pikilnyak, A. (2014). Ultrasonic facilities for the ground materials characteristics control, Metallurgical and Mining Industry, (2), 31-35.

14. Morkun, V., Morkun, N., \& Pikilnyak, A. (2014). Simulation of high-energy ultrasound propagation in heterogeneous medium using k-space method, Metallurgical and Mining Industry, (3), 23-27.

15. Morkun, V., Morkun, N., \& Pikilnyak, A. (2014). Simulation of the Lamb waves propagation on the plate which contacts with gas containing iron ore pulp in Waveform Revealer toolbox, Metallurgical and Mining Industry, (5), 16-19.

16. Sinchuk, O., Sinchuk, I., Kozakevych, I., Fedotov, V., Serebrenikov, V., Lokhman, N., Beridze, T., Boiko, S., Pyrozhenko, A., \& Yalova, A. (2018). Development of the functional model to control the levels of electricity consumption by underground ironore enterprises. EasternEuropean Journal of Enterprise Technologies, 6(3(96)), 20-27. https://doi.org/10.15587/1729$\underline{4061.2018 .148606}$

17. Morkun, V., Morkun, N., \& Pikilnyak, A. (2014). Ultrasonic phased array parameters determination for the gas bubble size distribution control formation in the iron ore flotation, Metallurgical and Mining Industry, (3), 28-31.

18. Morkun, V., Morkun, N., Pikilnyak, A. (2014). The gas bubble size distribution control formation in the flotation process, Metallurgical and Mining Industry, (4), 42-45.

19. Golik, V., Komashchenko, V., \& Morkun, V. (2015). Geomechanical terms of use of the mill tailings for preparation, Metallurgical and Mining Industry, (4), 321-324.

20. Golik, V., Komashchenko, V., Morkun, V., \& Burdzieva, O. (2015). Metal deposits combined development experience, Metallurgical and Mining Industry, (6), 591-594.

21. Golik, V., Mitsik, M., Morkun, V., Morkun, N., \& Tron, V. (2019). Transportation of 
concentration and leaching tailings in underground mining of metal deposits. Mining of Mineral Deposits, 13(2), 111-120. https://doi.org/10.33271/mining13.02.111

22. Naidoo, M. A., Olivier, L. E., \& Craig, I. K. (2013). Combined neural network and particle filter state estimation with application to a run-of-mine ore mill. IFAC Proceedings Volumes, 46(32), 397-402. https://doi.org/10.3182/20131218-3-in-2045.00103

23. Hadizadeh, M., Farzanegan, A., \& Noaparast, M. (2018). A plant-scale validated MATLABbased fuzzy expert system to control SAG mill circuits. Journal of Process Control, (70), 1-11. https://doi.org/10.1016/j.jprocont.2018.08.003

24. Aguila-Camacho, N., Le Roux, J.D., Duarte-Mermoud, M.A., \& Orchard, M.E. (2017). Control of a grinding mill circuit using fractional order controllers. Journal of Process Control, (53), 80-94. https://doi.org/10.1016/j.jprocont.2017.02.012

25. Sage, A.P., \& White, I.Ch. (1982). Optimalnoe upravlenie sistemami. Moskva: Radio i svyaz'.

26. Sage, A.P., \& Melsa J.L. (1966). Identifikatsiya sistem upravleniya. Moskva: Nauka.

27. Lee, R. (1966). Optimalnye otsenki, opredelenie kharakteristik i upravlenie. Moskva: Nauka. 